\title{
Classification of metabolic syndrome according to lipid alterations: analysis from the Mexican National Health and Nutrition Survey 2006
}

\author{
Andrea Pedroza-Tobias', Belem Trejo-Valdivia', Luz M Sanchez-Romero ${ }^{1,2}$ and Simon Barquera ${ }^{1 *}$
}

\begin{abstract}
Background: There are 16 possible Metabolic Syndrome (MS) combinations out of 5 conditions (glucose intolerance, low levels of high-density lipoprotein Cholesterol (HDL-C), high triglycerides, high blood pressure and abdominal obesity), when selecting those with at least three. Studies suggest that some combinations have different cardiovascular risk. However evaluation of all 16 combinations is complex and difficult to interpret. The purpose of this study is to describe and explore a classification of MS groups according to their lipid alterations.

Methods: This is a cross-sectional study with data from the Mexican National Health and Nutrition Survey 2006. Subjects $(n=5,306)$ were evaluated for the presence of MS; four mutually-exclusive MS groups were considered: mixed dyslipidemia (altered triglycerides and HDL-C), hypoalphalipoproteinemia: (normal triglycerides but low $\mathrm{HDL}-\mathrm{C}$ ), hypertriglyceridemia (elevated triglycerides and normal $\mathrm{HDL}-\mathrm{C}$ ) and without dyslipidemia (normal triglycerides and $\mathrm{HDL}-\mathrm{C}$ ). A multinomial logistic regression model was fitted in order to identify characteristics that were associated with the groups.
\end{abstract}

Results: The most frequent MS group was hypoalphalipoproteinemia in females (51.3\%) and mixed dyslipidemia in males (43.5\%). The most prevalent combination of MS for both genders was low HDL-C + hypertension + abdominal obesity (20.4\% females, $19.4 \%$ males). The hypoalphalipoproteinemia group was characteristic of women and less developed areas of the country. The group without dyslipidemia was more frequent in the highest socioeconomic level and less prevalent in the south of the country. The mixed dyslipidemia group was characteristic of men, and the Mexico City region.

Conclusions: A simple system to classify MS based on lipid alterations was useful to evaluate prevalences by diverse biologic and sociodemographic characteristics. This system may allow prevention and early detection strategies with emphasis on population-specific components and may serve as a guide for future studies on MS and cardiovascular risk.

Keywords: Metabolic syndrome, Dyslipidemias, Triglycerides, HDL cholesterol, Mexico

\section{Background}

In recent years, Mexico has undergone the so-called nutritional transition in which dietary and physical activity patterns have changed, bringing with it a change in chronic disease patterns and a decrease in infectious diseases [1]. However, the level of this transition varies depending on the geographical area of the country. Mexico's southern region is the least developed region. It is characterized by a traditional diet and a higher

\footnotetext{
* Correspondence: sbarquera@insp.mx

'Instituto Nacional de Salud Publica, Cuernavaca, Morelos, México

Full list of author information is available at the end of the article
}

level of physical activity, while the northern region is more developed and its population usually consumes an energy dense diet rich in sugar, fat and sodium [2].

Metabolic syndrome (MS) refers to a combination of metabolic risk factors that lead to cardiovascular events (CVE) $[3,4]$. According to the most recent classification for MS, at least three of the following altered conditions are required in order to arrive at a diagnosis: high waist circumference, high blood pressure, high triglycerides, low high-density lipoprotein cholesterol (HDL-C) and high fasting glucose [4]. These criteria allow for sixteen 
possible combinations of MS that do not necessarily involve the same cardiovascular risk.

Some studies have identified combinations of components of MS that have a higher risk of CVE, cerebrovascular events and mortality [5-9]. Additionally, it has been shown that low HDL-C levels and high triglyceride levels are an independent risk factor for cardiovascular disease [10-12]. Moreover, it has been proposed to use the triglyceride/HDL-C ratio as a marker of cardiovascular risk and insulin resistance [12].

According to the 2006 Mexican National Health and Nutrition Survey (ENSANUT from its Spanish acronym), the prevalence of MS in Mexico approaches 49.8\% (47.5\%-52.1\%) in the adult population ( $\geq 20$ years old) [13]. Although 31.5\% of Mexican adults have hypertriglyceridemia, only $3.8 \%$ of the population reported to been previously diagnosed, thus making this one of the main national challenges for public health [14].

This study focus on identifying and describing MS groups based on the presence of hypertriglyceridemia and/or hypoalphalipoproteinema since they play an important role in the development of MS, insulin resistance and cardiovascular risk, and are generally asymptomatic.

\section{Methods}

A secondary analysis was carried out on data obtained from the ENSANUT 2006. This survey was conducted from October 2005 to May 2006. ENSANUT 2006 is a probabilistic, cluster-stratified survey with national, regional and state representation that collected health, nutrition and sociodemographic information from 48,600 households. In addition, fasting venous blood samples were obtained from a randomized subsample designed with adequate power to detect conditions with a prevalence of at least $8 \%$ at the national level, by region and urban/rural location, resulting in a total of 6,021 subjects $\geq 20$ y [15]. The sampling weights were calculated considering the age and sex distribution of the Mexican National population census. No statistically significant differences were found in biological and socio-economic characteristics between the subsample and the whole adult ENSANUT 2006 sample [13]. The present analysis was conducted in 2012-2013.

\section{Data collection}

Trained surveyors administered a standardized questionnaire to the subjects in order to obtain personal data such as age, level of education, socioeconomic level, alcohol and tobacco consumption, as well as chronic disease diagnostic and treatment information [16].

Anthropometric information was obtained using standard procedures by trained personnel. Waist circumference was measured at the midpoint between the highest part of the iliac crest and the lowest part of the ribs margin of the median axial line $[15,16]$.

Serum glucose concentrations were measured using an automatized glucose oxidase method, with an overall inter-assay coefficient of variation $(\mathrm{CV})$ of $<5 \%$. Serum triglyceride concentrations were measured after lipase hydrolysis in an automatic analyzer with a tungsten lamp. The inter-assay CV was $5.7 \%$. HDL-C was measured by an enzymatic colorimetric direct method after eliminating chylomicrons, very-low-density lipoproteins (VLDL), and low-density lipoproteins by enzymatic digestion; the inter-assay CV was $5.02 \%[15,16]$.

Details on the methodology for anthropometric, clinical and biochemical measurements, as well as the methods used to calculate the sample, have been reported in previous publications $[15,16]$.

The country was divided into four geographic regions for analysis. The Northern region, includes the states of Baja California, Baja California Sur, Coahuila, Chihuahua, Durango, Nuevo Leon, Sonora and Tamaulipas; the Central region, the states of Aguascalientes, Colima, Guanajuato, Jalisco, Mexico, Michoacan, Morelos, Nayarit, Queretaro, San Luis Potosi, Sinaloa and Zacatecas; the Mexico City region; and the Southern region, the states of Campeche, Chiapas, Guerrero, Hidalgo, Oaxaca, Puebla, Quintana Roo, Tabasco, Tlaxcala, Veracruz and Yucatan.

A principal component analysis of household appliances and community conditions was estimated as a proxy for socio-economic level (SEL). The variables included in the analysis were household characteristics (floor and ceiling material, total number of rooms in the household), number of persons residing in the household, possession of refrigerator, washing machine and stove and the number of electric appliances in the household (radio, TV, video player, telephone, and computer). The main first principal component explained $40.4 \%$ of the total variance with a Kaiser-Mayer-Olkin measure of sampling adequacy equal to 0.83 . The range of the first principal component scores was divided into tertiles and used as a proxy for low, medium and high SEL [16].

\section{Diagnosis of metabolic syndrome}

The diagnosis of MS was made when at least 3 components of MS were altered according to the harmonized criteria of the International Diabetes Federation (IDF), World Health Organization (WHO), National Heart, Lung and Blood Institute (NHLBI), International Atherosclerosis Society and the International Association for the Study of Obesity [4] (Table 1).

\section{Metabolic syndrome groups}

Combinations of MS were grouped in relation to the presence of hypertriglyceridemia and hypoalphalipoproteinemia 
Table 1 Criteria for metabolic syndrome diagnosis

\begin{tabular}{lc}
\hline Conditions & Cutoff points \\
\hline $\begin{array}{l}\text { Hypertension }(\mathrm{mm} \mathrm{Hg}) \text { or drug treatment } \\
\text { for hypertension control }\end{array}$ & $\geq 130 / 85$ \\
Tryglicerides (mg/dL) & $\geq 150$ \\
High density lipoprotein cholesterol (mg/dL) & \\
$\quad$ Men & $<40$ \\
$\quad$ Women & $<50$ \\
Waist Circumference $(\mathrm{cm})$ & $\geq 90$ \\
$\quad$ Men & $\geq 80$ \\
$\quad$ Women & $\geq 100$ \\
\hline Glucose $(\mathrm{mg} / \mathrm{dl})$ or drug treatment for glucose control
\end{tabular}

Adapted from Alberti KGMM. et al. [4].

(Three or more conditions).

into 4 mutually-exclusive groups: the mixed dyslipidemia group consisted of those with altered triglyceride and HDL-C levels; the hypoalphalipoproteinemia group consisted of those subjects with normal triglyceride levels but low HDL-C levels; the hypertriglyceridemia group had subjects with elevated triglyceride levels but normal HDL$\mathrm{C}$ levels; and the no dyslipidemia group were subjects with normal triglyceride and HDL-C levels.

\section{Statistical analysis}

\section{Exploratory analysis}

For comparison between different groups, analysis of variance was used for continuous variables and $x^{2}$ or difference between proportions tests were used for categorical variables. The Bonferroni correction was used in multiple comparisons [17].

\section{Inferential statistics}

In order to predict the group in which an individual belongs with the highest probability, an unconditional multinomial logistic regression model was fitted in which the reference MS group was the mixed dyslipidemia. The dependent variable was the categorical variable indicating the MS group to which the individual belonged and the independent variables were sex, age, geographic region, location, SEL tertile, level of education, nutritional state and previous diagnosis of diabetes and hypertension. The Hosmer-Lemeshow test was performed to assess the goodness of fit of the model [18].

Estimation procedures included sampling weights to adjust for the sample complex design. Analysis was carried out using the SVY module for complex samples with the STATA version 11.1 statistical package.

\section{Ethical considerations}

Because this is a secondary study, the investigators have no access to the subject's personal information. Originally, for the ENSANUT 2006, the participants were informed about the objectives of the survey, the methodology used and consent to participate was obtained. This protocol and the ENSANUT protocol was approved by the Ethics Committee at the Mexican National Institute of Public Health.

\section{Results}

For this study, we included cases reporting at least eight hours of fasting at the time the blood sample was collected $(n=6021)$. We excluded pregnant women $(n=95)$, and 620 cases with missing data or samples with biological implausible data for glucose $(<30 \mathrm{mg} / \mathrm{dl})$, HDL-C and triglycerides $(<10 \mathrm{mg} / \mathrm{dl})$, waist circumference $(<50 \mathrm{~cm})$ or blood pressure (systolic blood pressure $<80 \mathrm{mmHg}$ or diastolic blood pressure $<50 \mathrm{mmHg}$ ) leaving a total analytic sample of 5,306 observations. An attrition analysis, based on sociodemographic variables as sex, age, SEL and residence area was carried out showing no significant differences between the subjects excluded and included.

The prevalence of MS in the Mexican population was 49.9\%. The most prevalent components were low HDLC (76.8\%) and abdominal obesity (73.6\%), while the least prevalent was hypertriglyceridemia (30.9\%). The prevalence of hypertension, abdominal obesity and high glucose was not statistically different between urban and rural areas, by geographic region, and by SEL $(p>0.05)$ (data not shown).

Seven percent of the subjects with elevated triglycerides reported to have been previously diagnosed, while more than $80 \%$ of subjects with elevated triglycerides had MS. $64.4 \%$ of subjects with abdominal obesity and $56.4 \%$ of subjects with low HDL-C had MS.

\section{Metabolic syndrome groups}

Table 2 shows the prevalence of the MS groups and combinations among them. The MS group with hypoalphalipoproteinemia was the most prevalent in the overall Mexican population (46.0\%), while the most frequent combination of MS was low HDL-C + high blood pressure (HBP) + abdominal obesity (AO) (20.0\%). The same MS group and combination was observed with the highest frequency in women as in the general population, while the group of MS with mixed dyslipidemia was most prevalent in men (43.5\%), with the most common combination in this group being hypertriglyceridemia (HTG) + low HDL-C + AO. The least prevalent group was MS without dyslipidemia (3.1).

\section{Sociodemographic characteristics of the MS groups}

The prevalence of MS was similar between men and women. However, when it was stratified by group, the hypoalphalipoproteinemia group was $31 \%$ more prevalent in women $(51.5 \%)$ than men $(39.2 \%)(p<0.05)$, while 
Table 2 Prevalence of metabolic syndrome groups and combinations stratified by sex

\begin{tabular}{|c|c|c|c|c|c|c|c|c|}
\hline & & & \multicolumn{2}{|r|}{ Overall } & \multicolumn{2}{|c|}{ Women } & \multicolumn{2}{|r|}{ Men } \\
\hline \multirow{2}{*}{\multicolumn{2}{|c|}{ Metabolic syndrome groups and combinations }} & $\begin{array}{l}\text { Number of } \\
\text { components } \\
\text { altered }\end{array}$ & & $n=2707$ & & $=1716$ & & $n=991$ \\
\hline & & & $\%$ & $95 \% \mathrm{Cl}$ & $\%$ & $95 \% \mathrm{Cl}$ & $\%$ & $95 \% \mathrm{Cl}$ \\
\hline \multicolumn{2}{|c|}{ Group 1: Mixed dyslipidemia } & & 40.7 & $(37.5,44.1)$ & 38.5 & $(34.5,42.6)$ & 43.5 & $(38.9,48.2)$ \\
\hline & Hypertension & 3 & 1.2 & $(0.7,2.1)$ & 0.4 & $(0.1,1.2)$ & 2.2 & $(1.2,4.0)$ \\
\hline & High Glucose & 3 & 1.5 & $(0.9,2.5)$ & 0.6 & $(0.3,1.2)$ & 2.6 & $(1.4,5.0)$ \\
\hline & Abdominal Obesity & 3 & 11.7 & $(9.7,14.0)$ & 11.6 & $(9.3,14.4)$ & 11.8 & $(8.5,16.0)$ \\
\hline \multirow{4}{*}{$\begin{array}{l}\text { Low HDL-C }+ \text { High } \\
\text { Triglycerides }+\end{array}$} & Hypertension + High Glucose & 4 & 0.4 & $(0.2,0.9)$ & 0.1 & $(0.0,0.3)$ & 0.9 & $(0.4,1.8)$ \\
\hline & Hypertension + Abdominal Obesity & 4 & 8.4 & $(6.7,10.4)$ & 8.8 & $(6.5,11.7)$ & 7.9 & $(5.9,10.5)$ \\
\hline & High Glucose + Abdominal Obesity & 4 & 7.6 & $(5.8,10.0)$ & 8.2 & $(5.7,11.7)$ & 6.9 & $(4.8,9.7)$ \\
\hline & $\begin{array}{l}\text { Hypertension + Abdominal Obesity + } \\
\text { High Glucose }\end{array}$ & 5 & 10.0 & $(8.3,12.1)$ & 8.9 & $(7.2,10.9)$ & 11.4 & $(8.5,15.1)$ \\
\hline \multicolumn{2}{|c|}{ Group 2: Hypoalphalipoproteinemia } & & 46.0 & $(42.6,49.5)$ & 51.6 & $(47.3,55.8)$ & 39.2 & $(34.7,44.0)$ \\
\hline \multirow{4}{*}{ Low HDL-C+ } & Hypertension + High Glucose & 3 & 1.4 & $(0.9,2.1)$ & 0.8 & $(0.4,2.0)$ & 2.0 & $(1.3,3.2)$ \\
\hline & Hypertension + Abdominal Obesity & 3 & 20.0 & $(17.6,22.6)$ & 20.4 & $(17.5,23.6)$ & 19.4 & $(15.8,23.7)$ \\
\hline & High Glucose + Abdominal Obesity & 3 & 11.7 & $(9.9,13.8)$ & 16.2 & $(13.3,19.4)$ & 6.2 & $(4.4,8.5)$ \\
\hline & $\begin{array}{l}\text { Hypertension + Abdominal Obesity + } \\
\text { High Glucose }\end{array}$ & 4 & 13.0 & $(11.3,14.9)$ & 14.1 & $(12.0,16.6)$ & 11.6 & $(9.1,14.7)$ \\
\hline \multicolumn{2}{|c|}{ Group 3: Hypertriglyceridemia } & & 10.2 & $(8.4,12.2)$ & 7.8 & $(5.9,10.2)$ & 13.1 & $(10.3,16.6)$ \\
\hline & Hypertension + High Glucose & 3 & 0.5 & $(0.3,1.2)$ & 0.1 & $(0.0,0.8)$ & 1.1 & $(0.4,2.4)$ \\
\hline \multirow{3}{*}{ High triglycerides+ } & Hypertension + Abdominal Obesity & 3 & 2.8 & $(2.0,3.8)$ & 2.1 & $(1.2,3.4)$ & 3.7 & $(2.5,5.6)$ \\
\hline & High Glucose alterada + Abdominal Obesity & 3 & 2.9 & $(2.1,4.0)$ & 3.1 & $(2.1,4.5)$ & 2.8 & $(1.6,4.8)$ \\
\hline & $\begin{array}{l}\text { Hypertension + Abdominal Obesity + High } \\
\text { Glucose }\end{array}$ & 4 & 3.9 & $(2.9,5.2)$ & 2.5 & $(1.6,3.9)$ & 5.5 & $(3.7,8.1)$ \\
\hline \multicolumn{2}{|c|}{ Group 4: Without dyslipidemia } & & 3.1 & $(2.154,4.353)$ & 2.2 & $(1.4,3.4)$ & 4.1 & $(2.5,6.8)$ \\
\hline & Hypertension + Abdominal Obesity + High Glucose & 3 & 3.1 & $(2.2,4.4)$ & 2.2 & $(1.4,3.4)$ & 4.1 & $(2.5,6.8)$ \\
\hline
\end{tabular}

hypertriglyceridemia group was $68 \%$ more prevalent in men $(13.1 \%)$ than in women $(7.8 \%)(p<0.05)$.

As age increased, the prevalence of MS also increased. This prevalence was $<30 \%$ in younger subjects, doubled in those older than $40 \mathrm{y}$, and was $>70 \%$ in subjects over $50 \mathrm{y}$. The prevalence of the mixed dyslipidemia group was slightly higher than $40 \%$ in subjects between $20-50 \mathrm{y}$. Nevertheless, a decrease of $30.3 \%$ was observed in those $\geq 60 \mathrm{y}$.

The prevalence of MS was higher in urban areas than in rural areas $(51.2 \%$ versus $45.1 \%, p<0.05)$. Similar results were seen in all MS groups except for the hypoalphalipoproteinemia group, which showed a $27 \%$ higher prevalence in rural than urban areas $(p<0.05)$.

The prevalence of MS was similar among the SEL tertiles. However, the hypoalphalipoproteinemia group was $22 \%$ more prevalent in the low SEL when compared to the high SEL tertile $(p<0.05)$ (Table 3$)$.

The predictors associated with belonging to the hypoalphalipoproteinemia group in the multinomial logistic regression model were being female and living in the northern region of the country when compared to living in Mexico City $(p<0.01)$. The factors that best predicted belonging to the hypertriglyceridemia group were being male, having over $50 \mathrm{y}$ and residing in Mexico City when compared to the northern region $(p<0.01)$. Finally, there was a lower probability of finding individuals without dyslipidemia in the southern region of the country $(p<0.05)$ (Table 4$)$.

\section{Discussion}

This study shows different MS groups as well as the prevalence of these groups according to sociodemographic variables. We classified four mutually exclusive groups of MS based on the absence or presence of changes in triglycerides and HDL-C since these factors play an important role in the development of MS, insulin resistance, and because they are major mediators in the atherogenic process. In addition, several studies have identified the lipid profile as an insulin resistance and cardiovascular risk marker $[11,12,19]$.

The prevalence of MS in our study was $49.9 \%$, only a $0.1 \%$ point higher than the one previously reported [13]. 
Table 3 Prevalence of metabolic syndrome and metabolic syndrome groups according to sociodemographic characteristics

\begin{tabular}{|c|c|c|c|c|c|c|}
\hline & & & & Metabolic syndro & me groups & \\
\hline & & $\begin{array}{l}\text { Metabolic } \\
\text { syndrome } \\
\text { (Overall) }\end{array}$ & $\begin{array}{c}\text { Mixed } \\
\text { dyslipidemia }\end{array}$ & Hypoalphalipoproteinemia & Hypertriglyceridemia & $\begin{array}{c}\text { Without } \\
\text { dyslipidemia }\end{array}$ \\
\hline & & $n=2707$ & $n=980$ & $n=1349$ & $\mathrm{n}=\mathbf{2 8 5}$ & $\mathrm{n}=93$ \\
\hline & $\mathbf{n}$ & $\%(95 \% \mathrm{Cl})$ & $\%(95 \% \mathrm{Cl})$ & $\%(95 \% \mathrm{Cl})$ & $\%(95 \% \mathrm{Cl})$ & $\%(95 \% \mathrm{Cl})$ \\
\hline Total $\mathbf{n}=\mathbf{2 7 0 7}$ & 2,707 & 49.9 & 40.7 & 46.0 & 10.2 & 3.1 \\
\hline Sex & & & & & & \\
\hline Women $^{a}$ & 1,716 & $50.4(47.5,53.3)$ & $38.5(34.5,42.6)$ & $51.5(47.3,55.8)$ & $7.8(5.9,10.2)$ & $2.2(1.4,3.4)$ \\
\hline Men & 991 & $49.4(45.9,52.8)$ & $43.5(38.9,48.2)$ & $39.2(34.7,44.0)^{a}$ & $13.1(10.3,16.5)^{a}$ & $4.1(2.5,6.8)$ \\
\hline Age & & & & & & \\
\hline $20-29^{a}$ & 295 & $27.1(22.9,31.8)^{b, c, d, e}$ & $45.4(35.6,55.5)$ & $47.0(37.6,56.6)$ & $4.4(2 \cdot 2,8.7)^{\mathrm{d}, \mathrm{e}}$ & $3.3(0.6,16.1)$ \\
\hline $30-39^{b}$ & 633 & $44.5(40.5,48.6)^{\mathrm{a}, \mathrm{c}, \mathrm{d}, \mathrm{e}}$ & $43.2(36.8,49.8)^{\mathrm{e}}$ & $44.8(38.5,51.2)$ & $10.6(6.8,16.0)$ & $1.5(0.8,2.9)$ \\
\hline $40-49^{c}$ & 638 & $62 \cdot 0(57 \cdot 2,66 \cdot 6)^{a, b}$ & $41.7(35.5,48.2)$ & $48.0(41.7,54.4)^{d}$ & $7.7(5.6,10.6)^{d}$ & $2.6(1.6,4.1)$ \\
\hline $50-59^{d}$ & 509 & $70.0(64.9,74.7)^{\mathrm{a}, \mathrm{b}}$ & $44.4(38.2,50.7)^{\mathrm{e}}$ & $36.1(30.6,42.1)^{\text {c,e }}$ & $16.2(12 \cdot 1,21.3)^{a, c}$ & $3.3(1.9,5.6)$ \\
\hline$\geq 60^{e}$ & 632 & $70.3(66.2,74.0)^{a, b}$ & $30.3(25.4,35.7)^{b, d}$ & $52.9(46.6,59.1)^{d}$ & $11.7(8.2,16.4)^{a}$ & $5.1(3.1,8.2)$ \\
\hline Area & & & & & & \\
\hline Rural $^{\mathrm{a}}$ & 774 & $45.1(41.2,49.1)$ & $35.5(30.2,41.1)$ & $55.7(50.2,61.1)$ & $6.8(4.9,9.6)$ & $2.0(1.2,3.2)$ \\
\hline Urban & 1,933 & $51.2(48.4,54.0)^{a}$ & $42.0(38.2,45.9)$ & $43.7(39.7,47.8)^{a}$ & $11 \cdot 0(8 \cdot 9,13.4)^{\mathrm{a}}$ & $3.3(2.2,4.9)$ \\
\hline Region & & & & & & \\
\hline North $^{a}$ & 714 & $50.7(47.3,54.2)$ & $35.8(30.2,41.9)$ & $49.8(43.8,55.8)^{c}$ & $9.6(6.5,13.8)^{c}$ & $4.8(3 \cdot 2,7.1)^{d}$ \\
\hline Center $^{\mathrm{b}}$ & 937 & $50.2(45.6,54.8)$ & $43.1(37.2,49.3)$ & $44.9(39.0,50.9)^{c, d}$ & $8.5(6.2,11.7)^{c}$ & $3.5(1.8,6.5)$ \\
\hline Mexico City ${ }^{c}$ & 97 & $56.4(44.9,67.2)$ & $57.9(48.0,67.3)^{d}$ & $10.5(5.4,19.3)^{a, b, d}$ & $29.5(20.7,40.2)^{a, b, d}$ & $2.1(0.3,11.7)$ \\
\hline South $^{d}$ & 959 & $47.3(44.3,50.3)$ & $35.7(31.2,40.4)^{c}$ & $55.9(51.0,60.7)^{\mathrm{b}, \mathrm{c}}$ & $6.9(5.2,9.1)^{c}$ & $1.5(0.9,2.7)^{\mathrm{a}}$ \\
\hline Socioeconomic Level & & & & & & \\
\hline Low $^{a}$ & 1,056 & $48.5(45.1,51.9)$ & $38.3(33.7,43.1)$ & $51.6(46.6,56.5)^{c}$ & $8.1(6.0,10.7)$ & $2.0(1.3,3.2)$ \\
\hline Middle $^{\mathrm{b}}$ & 961 & $51.3(48.0,54.7)$ & $42.5(37.4,47.7)$ & $45.1(40.2,50.1)$ & $10.5(7.9,13.9)$ & $1.9(1.2,3.0)$ \\
\hline $\mathrm{High}^{c}$ & 682 & $50.3(45.5,55.2)$ & $41.0(34.9,47.4)$ & $42.1(36.1,48.4)^{\mathrm{a}}$ & $11.5(8.2,15.9)$ & $5.3(3.0,9.1)$ \\
\hline Eduaction Level & & & & & & \\
\hline Less than elementary school ${ }^{a}$ & 1,739 & $57.4(54.7,60.1)$ & $37.7(33.8,41.7)$ & $49.3(45.2,53.3)$ & $9.9(8.0,12.2)$ & $3.2(2.3,4.4)$ \\
\hline Elementary school or higher & 965 & $42.9(39.5,46.4)^{\mathrm{a}}$ & $44.8(39.3,50.3)$ & $41.7(36.4,47.3)$ & $10.5(7.8,14.1)$ & $3.0(1.5,6.0)$ \\
\hline Diabetes previously diagnosed & 677 & $79.7(75.2,83.5)$ & $35.9(30.5,41.6)$ & $49.0(43.0,55.0)$ & $11.1(7.8,15.4)$ & 4.0(2.4,6.6) \\
\hline Hypertension previously diagnosed & 332 & $89.0(82.3,93.4)$ & $38.5(30.7,46.9)$ & $50.5(41.7,59.3)$ & $9.1(5.6,14.4)$ & $1.9(0.9,3.9)$ \\
\hline $\begin{array}{l}\text { Hypertriglyceridemia previously } \\
\text { diagnosed }\end{array}$ & 175 & $76.3(67.2,83.4)$ & $42.8(33.1,53.2)$ & $38.5(28.6,49.4)$ & $15.5(8.7,26.1)$ & $3.2(1.1,8.7)$ \\
\hline Body Mass Index Category $(\mathrm{Kg} / \mathrm{m}$ & & & & & & \\
\hline $18.5-24.9^{a}$ & 348 & $23.8(20.2,27.9)^{\mathrm{b}, \mathrm{c}}$ & $46.0(37.5,54.8)$ & $40.6(33.4,48.3)$ & $10.3(6.9,15.0)$ & $3.2(1.2,7.7)$ \\
\hline $25-29.9^{b}$ & 1,122 & $54.2(50.6,57.7)^{a, c}$ & $40.8(36.2,45.5)$ & $45.2(40.3,50.2)$ & $10.7(8.2,14.0)$ & $3.3(1.7,6.2)$ \\
\hline$\geq 30^{c}$ & 1,203 & $73.9(70.7,76.9)^{a, b}$ & $38.4(33.6,43.4)$ & $49.2(44.3,54.2)$ & $9.6(7.3,12.6)$ & $2.8(1.9,3.9)$ \\
\hline
\end{tabular}

$\bar{a}, \mathrm{~b}, \mathrm{c}, \mathrm{d}, \mathrm{e} P$ Value $<0.05$ for difference between proportions when comparing between categories of sociodemographic characteristics, with Bonferroni Adjustment.

This difference is explained by our selection criteria where cases with at least one missing value in any MS component were excluded from the analytic sample.

While MS appears to be characteristic of certain population groups such as older subjects and those living in urban areas, a similar distribution was observed by SEL tertile. When MS was stratified by group, the following characteristics were observed:

\section{Mixed dyslipidemia group}

The principal finding in this group was the decreased prevalence in subjects $\geq 60 \mathrm{y}$, which may be explained by a 
Table 4 Sociodemographic predictors of metabolic syndrome groups

\begin{tabular}{|c|c|c|c|c|c|c|c|}
\hline \multirow[b]{2}{*}{ Sex (women) } & $\begin{array}{l}\text { Mixed dyslipidemia } \\
\quad \text { OR }(95 \% \mathrm{Cl})\end{array}$ & \multicolumn{2}{|c|}{$\frac{\text { Hypoalphalipoproteinemia }}{\text { OR }(95 \% \mathrm{Cl})}$} & \multicolumn{2}{|c|}{$\frac{\text { Hypertrigliceridemia }}{\mathrm{OR}(95 \% \mathrm{Cl})}$} & \multicolumn{2}{|c|}{$\frac{\text { Without dyslipidemia }}{\text { OR }(95 \% \mathrm{Cl})}$} \\
\hline & & & & & & & \\
\hline Men & 1.0 & $0.69^{* *}$ & $(0.53,0.91)$ & $1.71^{* *}$ & $(1.14,2.55)$ & 1.61 & $(0.93,2.77)$ \\
\hline \multicolumn{8}{|l|}{ Age (20-29 years) } \\
\hline 30-39 years & 1.0 & 0.99 & $(0.60,1.63)$ & $2.71^{*}$ & $(1.09,6.74)$ & 0.39 & $(0.06,2.65)$ \\
\hline $40-49$ years & 1.0 & 0.99 & $(0.62,1.59)$ & 1.94 & $(0.79,4.72)$ & 0.86 & $(0.15,4.97)$ \\
\hline $50-59$ years & 1.0 & 0.70 & $(0.42,1.16)$ & $4.31^{* *}$ & $(1.74,10.70)$ & 1.05 & $(0.15,7.10)$ \\
\hline$\geq 60$ years & 1.0 & 1.51 & $(0.91,2.48)$ & $4.36^{* *}$ & $(1.63,11.71)$ & 2.47 & $(0.49,12.29)$ \\
\hline \multicolumn{8}{|l|}{ Area (Rural) } \\
\hline Urban & 1.0 & 0.83 & $(0.61,1.14)$ & 1.07 & $(0.64,1.79)$ & 1.11 & $(0.55,2.22)$ \\
\hline \multicolumn{8}{|l|}{ Region (North) } \\
\hline Central & 1.0 & 0.78 & $(0.53,1.13)$ & 0.73 & $(0.40,1.34)$ & 0.69 & $(0.30,1.59)$ \\
\hline Federal District & 1.0 & $0.12^{* *}$ & $(0.05,0.27)$ & $1.92^{*}$ & $(1.01,3.67)$ & 0.27 & $(0.04,1.95)$ \\
\hline South & 1.0 & 1.07 & $(0.75,1.54)$ & 0.79 & $(0.44,1.39)$ & $0.43^{*}$ & $(0.19,0.99)$ \\
\hline \multicolumn{8}{|l|}{ Socioeconomic Level (Low) } \\
\hline Middle & 1.0 & 0.92 & $(0.69,1.24)$ & 1.11 & $(0.67,1.83)$ & 0.80 & $(0.38,1.68)$ \\
\hline High & 1.0 & 0.99 & $(0.68,1.44)$ & 1.19 & $(0.65,2.19)$ & 2.29 & $(0.88,5.91)$ \\
\hline \multicolumn{8}{|l|}{ Education Level (Less than primary) } \\
\hline Primary or higher & 1.0 & 0.93 & $(0.68,1.28)$ & 0.96 & $(0.61,1.54)$ & 0.73 & $(0.39,1.37)$ \\
\hline \multicolumn{8}{|l|}{ Body mass Index Category (Normal) } \\
\hline Overweight & 1.0 & 1.37 & $(0.89,2.12)$ & 1.04 & $(0.57,1.89)$ & 1.27 & $(0.33,4.83)$ \\
\hline Obesity & 1.0 & 1.5 & $(0.97,2.31)$ & 1.14 & $(0.62,2.09)$ & 1.20 & $(0.35,4.07)$ \\
\hline Diabetes previously diagnosed & 1.0 & 1.17 & $(0.78,1.76)$ & 0.71 & $(0.40,1.26)$ & 0.47 & $(0.19,1.14)$ \\
\hline Hypertension previously diagnosed & 1.0 & 1.24 & $(0.90,1.70)$ & 1.03 & $(0.63,1.69)$ & 1.26 & $(0.64,2.50)$ \\
\hline
\end{tabular}

${ }^{* * *} p$ Value $<0.01$, Multinomial regression Model. Reference group: Mixed Dyslipidemia.

**P Value $<0.05$, Multinomial regression Model. Reference group: Mixed Dyslipidemia.

higher risk of mortality in the combined presence of low HDL-C and hypertriglyceridemia. Mazza et al. followed 3,257 women for 12 years and found that those in the lowest HDL-C quintile and the highest triglycerides quintile had a mortality risk almost three times higher than women in the highest HDL-C quintile or those in the lowest triglycerides quintile [11].

\section{Hypertriglyceridemia group}

This group was more prevalent in men, in the Mexico City region and in subjects $\geq 50 \mathrm{y}$. It has been reported that a high consumption of alcoholic beverages and simple carbohydrates increase the risk of hypertriglyceridemia. A report of the ENSANUT 2006 revealed that consumption of alcoholic and sugar sweetened beverages was higher in men than in women, with the latter being the primary source of simple sugars in the Mexican diet $[20,21]$.

The fact that this group was more prevalent in Mexico City may be explained by the lifestyle of its inhabitants, which include a higher consumption of industrialized food, and lower physical activity levels compared to the rest of the regions [22,23]. However, these results should be interpreted with caution since the sample size in this region was small when compared to other regions.

\section{Hypoalphalipoproteinemia group}

The hypoalphalipoproteinemia group was more prevalent in the south region, low SEL and rural areas. High total fat, mono and polyunsaturated fatty acids consumption increases HDL-C concentrations [24,25]. Therefore, differences in dietary patterns among regions of the country could partially explain variations in MS groups. Studies of ENSANUT, that evaluated the distribution of fat consumption by sociodemographic characteristics, found that around $60 \%$ have a low consumption of polyunsaturated fats, and a lower total fat and mono- and polyunsaturated fat consumption was found in rural locations, in the southern region of the country and in subjects in the lowest SEL $[21,26]$. Another possible explanation for 
low HDL-C and normal triglycerides is the higher prevalence of physical activity in this population given that physical activity has been associated with an increase in lipoprotein lipase activity, which produces a decrease in triglyceride levels [27]. According to ENSANUT 2006, the prevalence of physical activity was higher in these locations [22].

The hypoalphalipoproteinemia group was more prevalent in women when compared to men. The difference in prevalence between men and women in the MS groups with normal HDL-C may be explained by the different cutoff points for hypoalphalipoproteinemia between genders. The harmonized MS criteria and the ADA proposed different cutoff points for HDL-C between men and women $(<40 \mathrm{mg} / \mathrm{dl}$ in $\mathrm{men} ;<50 \mathrm{mg} / \mathrm{dl}$ in women) $[4,28]$. These differences have been proposed because the average HDL-C levels are higher in women than in men, and having the same cutoff point would diagnose more men than women. Nevertheless, it does not necessarily mean that the risk is different [29]. HDL$\mathrm{C}$ levels according to gender have been studied in other populations; Davis et al. evaluated mean HDL-C levels in men and women in six countries and found that women had higher HDL-C levels on average. However, there was great variability found among populations. The highest difference found between men and women $(15.6 \mathrm{mg} / \mathrm{dl})$ was reported in Canada while a smaller difference $(2.3 \mathrm{mg} / \mathrm{dl})$ was found in China [30]. Differences between men and women Korean adults were similar than those in the Chinese population $(2.5 \mathrm{mg} / \mathrm{dl})$ [31].

In our population, the age-adjusted difference in HDL$\mathrm{C}$ by gender was $3.2 \mathrm{mg} / \mathrm{dl}(38.9 \mathrm{mg} / \mathrm{dl}$ in women and $35.7 \mathrm{mg} / \mathrm{dl}$ in men), similar to that seen in the Chinese and Korean populations. When the 40 and $50 \mathrm{mg} / \mathrm{dl}$ cutoff points were used for men and women respectively, the prevalence of hypoalphalipoproteinemia was $68.7 \%$ for men and $83.6 \%$ for women, but when the $40 \mathrm{mg} / \mathrm{dl}$ cutoff point was used for both genders, the prevalence of hypoalphalipoproteinemia in women decreased by 27.6 percentage points and the prevalence was even higher in men than in women (68.7\% versus $56.0 \%)$. In addition, the prevalence of MS in women decreased from $50.4 \%$ to $42.4 \%$ and the prevalence of MS with normal HDL-C (hypertriglyceridemia and no dyslipidemia groups) increased from $10 \%$ to $29 \%$.

The use of different criteria for hypoalphalipoproteinemia by gender in the Mexican population does not appear to be completely justified given the similarity in HDL-C levels by gender. When these criteria are applied, the prevalence of MS and its groups may be differentially affected. Given that the cutoff points of $40 \mathrm{mg} /$ $\mathrm{dl}$ and $50 \mathrm{mg} / \mathrm{dl}$ were made based on the large HDL-C differences found between genders in other populations, it may be advisable to rethink these cutoff points for the
Mexican population as well as for other populations in which the difference in HDL-C by gender is very small, as seen in the Korean and Chinese populations [30,31].

\section{Group without dyslipidemia}

Unlike the hypoalphalipoproteinemia group, the group without dyslipidemia was uncommon in the south region of the country and in the low socioeconomic level group. This may also be explained by the quality of diet in this population [21].

One of the most interesting results found in this study is the low level of medical diagnoses of hypertriglyceridemia. Nevertheless, $80 \%$ of the subjects with elevated triglyceride levels had MS. Thus, it may be advisable to include serum triglyceride measurements in routine medical evaluations, as this is an area of opportunity for preventing cardiovascular events given that hypertriglyceridemia is a modifiable risk factor.

One of the limitations of this study is that there was not sufficient power to include more analytical variables such as dietary and physical activity characteristics that may contribute to explain the sociodemographic differences between the different MS groups. Given that this is a cross-sectional analysis derived from a national survey in which additional measurements of cardiovascular risk were not collected, it was not possible to identify groups or combinations with a higher cardiovascular risk.

There is no general agreement regarding an adequate waist circumference cutoff point for the Mexican population due to significant differences in height and body composition compared to Caucasians and other ethnic groups. However, the latest IDF MS definition recommends a lower cutoff point for central and South American populations [4]. Besides, a major sensitivity analysis in Mexican population showed that the IDF cutoff point had a better sensitivity for detection of diabetes, hypertension and metabolic syndrome, compared with the AHA cutoff point [32].

Other authors have described groups based on different MS components such as abdominal obesity [33]. However the MS groups based on lipid alterations seem to be useful because in our population $95 \%$ of the subjects with MS have abdominal obesity, therefore grouping MS using this factor does not provide balanced groups useful to characterizing the condition. In addition, the distribution of the other components (high glucose, hypertension and abdominal obesity) in the subjects with MS, among area, geographic region and SEL was not significantly different. A factor analysis of information coming from African population showed that the strongest predictors for MS were high blood pressure, triglycerides and HDL-C, which could support our MS classification [34]. 


\section{Conclusions}

The MS classification proposed here could be useful to describe different characteristics of this condition. From a public health perspective, this approach could be helpful to identify and to target prevention, treatment and early detection interventions according to demographic and biological characteristics. For example, for the population living in the south of Mexico in rural areas and with low SEL, an intervention could be focused on increasing the consumption of mono and polyunsaturated fatty acids while in the central region of the country and Mexico City the promotion of physical activity could be more important given the most prevalent groups in those regions (hypoalphalipoproteinemia group and hypertriglyceridemia group respectively).

This is the first study in Mexico to describe and classify groups of MS combinations. Subsequent analyses could evaluate these groups to better understand the different cardiovascular and metabolic outcomes associated.

\section{Competing interests}

The authors declare that they have no competing interests.

\section{Authors' contributions}

APT was in charge of the statistical analysis and writing the manuscript. LMSR made contributions to the manuscript. BTV contributed to the statistical analysis and SBC designed research, participated in the study design and helped to write the manuscript. All authors read and approved the final manuscript.

\section{Acknowledgements}

This study was funded by NIH-FOGARTY RO3 TW009061 grant and a scholarship from CONACYT. The authors would like to thank Ruy LopezRidaura, Lucia Hernandez-Barrera and Juan Rivera for their support.

\section{Author details}

${ }^{1}$ Instituto Nacional de Salud Publica, Cuernavaca, Morelos, México. ${ }^{2}$ Department of Epidemiology and Public Health, University College London, London, UK.

Received: 27 June 2014 Accepted: 23 September 2014 Published: 9 October 2014

\section{References}

1. Omran AR: The epidemiologic transition: a theory of the epidemiology of population change. 1971. Milbank Q 2005, 83(4):731-757.

2. Stevens G, Dias RH, Thomas KJ, Rivera J, Carvalho N, Barquera S, Hill K, Ezzati M: Characterizing the epidemiological transition in Mexico: national and subnational burden of diseases, injuries, and risk factors. PLoS Med 2008, 5(6):e125.

3. Grundy SM, Brewer HB, Cleeman Jl, Smith SC, Lenfant C, National Heart, Lung and Blood Institute; American Heart Association: Definition of metabolic syndrome: Report of the National Heart, Lung, and Blood Institute/American Heart Association conference on scientific issues related to definition. Circulation 2004, 109(3):433-438.

4. Alberti KG, Eckel RH, Grundy SM, Zimmet PZ, Cleeman II, Donato KA Fruchart JC, James WP, Loria CM, Smith SC Jr, International Diabetes Federation Task Force on Epidemiology and Prevention; Hational Heart, Lung, and Blood Institute; American Heart Association; World Heart Federation; International Atherosclerosis Society; International Association for the Study of Obesity: Harmonizing the metabolic syndrome: a joint interim statement of the International Diabetes Federation Task Force on Epidemiology and Prevention; National Heart, Lung, and Blood Institute; American Heart Association; World Heart Federation; International. Circulation 2009, 120(16):1640-1645.
5. Moebus S, Balijepalli C, Lösch C, Göres L, Von Stritzky B, Bramlage P, Wasem J, Jöckel KH: Age- and sex-specific prevalence and ten-year risk for cardiovascular disease of all 16 risk factor combinations of the metabolic syndrome - a cross-sectional study. Cardiovasc Diabetol 2010, 9(1):34.

6. Hong $Y$, Jin $X, M o J$, Lin HM, Duan $Y$, Pu M, Wolbrette DL, Liao D: Metabolic syndrome, its preeminent clusters, incident coronary heart disease and all-cause mortality - results of prospective analysis for the Atherosclerosis Risk in Communities study. J Intern Med 2007, 262:113-124.

7. Rodriguez-Colon SM, Mo J, Duan Y, Liu J, Caulfield JE, Liao D: Metabolic Syndrome Clusters and the Risk of incident Stroke. The atherosclerosis risk in communities (ARIC) Study. Stroke 2009, 40:200-205.

8. Aekplakorn W, Kessomboon P, Sangthong R, Chariyalertsak S, Putwatana P, Inthawong R, Nitiyanant W, Taneepanichskul S, NHES IV study group: Urban and rural variation in clustering of metabolic syndrome components in the Thai population : results from the fourth National Health Examination Survey 2009. BMC Public Health 2011, 11(1):854.

9. Kim JY, Mun HS, Lee BK, Yoon SB, Choi EY, Min PK, Yoon YW, Hong BK, Rim $\mathrm{SJ}$, Kwon HM: Impact of metabolic syndrome and its individual components on the presence and severity of angiographic coronary artery disease. Yonsei Med J 2010, 51(5):676-682

10. Jeppesen J, Hein HO, Suadicani P, Gyntelberg F: Relation of high TG-Low $\mathrm{HDL}$ cholesterol and LDL cholesterol to the incidence of ischemic heart disease: an 8-year follow-up in the Copenhagen male study. Arterioscler Thromb Vasc Biol 1997, 17(6):1114-1120.

11. Mazza A, Tikhonoff V, Schiavon L, Casiglia E: Triglycerides + high-densitylipoprotein-cholesterol dyslipidaemia, a coronary risk factor in elderly women: the CArdiovascular STudy in the ELderly. Intern Med J 2005, 35(10):604-610.

12. McLaughlin T, Reaven G, Abbasi F, Lamendola C, Saad M, Waters D, Simon J, Krauss RM: Is there a simple Way to identify insulin-resistant individuals at increased risk of cardiovascular disease? Am J Cardiol 2005, 96:399-404.

13. Rojas R, Aguilar-Salinas CA, Jiménez-Corona A, Shamah-Levy T, Rauda J, Avila-Burgos L, Villalpando S, Ponce EL: Metabolic syndrome in Mexican adults. Results from the National Health and Nutrition Survey 2006. Salud Publica Mex 2010, 52(supl 1):s11-s18.

14. Aguilar-Salinas CA, Gómez-Pérez FJ, Rull J, Villalpando S, Barquera S, Rojas R: Prevalence of dyslipidemias in the Mexican National Health and Nutrition Survey 2006. Salud Publica Mex 2010, 52(supl 1):s44-s53.

15. Barquera S, Campos-Nonato I, Carrión-Rábago C, Villalpando S, LópezRidaura R, Rojas R, Aguilar-Salinas C: Methodology for the analysis of type 2 diabetes, metabolic syndrome and cardiovascular disease risk indicators in the ENSANUT 2006. Salud Publica Mex 2010, 52(supl 1):s4-s10.

16. Olaiz G, Rivera-Dommarco JA, Shamah-Levy T, Rojas-martínez R, Villalpando S, Hernández-ávila M: Encuesta Nacional de Salud y Nutrición 2006. Morelos: Cuernavaca; 2006.

17. Abdi H: The Bonferonni and Šidák Corrections for Multiple Comparisons In Encyclopedia of Measurement and Statistics. 1st edition. Edited by Salkind N. Thousands Oaks CA: SAGE Publications Inc.; 2007.

18. Fagerland MW, Hosmer DW: A generalized Hosmer-Lemeshow goodnesof-fit test for multinomial logistic regression models. Stata J 2012, 12(3):447-453

19. McLaughlin T, Abbasi F, Cheal K, Chu J, Lamendola C, Reaven G: Use of metabolic markers to identify overweight individuals who are insulin resistant. Ann Intern Med 2003, 139(10):802-809.

20. Barquera S, Hernandez-Barrera L, Tolentino ML, Espinosa J, Ng SW, Rivera JA, Popkin BM: Energy intake from beverages is increasing among Mexican adolescents and adults. J Nutr 2008, 138:2454-2461.

21. Barquera S, Hernández-Barrera L, Campos-Nonato I, Espinosa J, Flores M, AB J, Rivera JA: Energy and nutrient consumption in adults: analysis of the Mexican National Health and Nutrition Survey 2006. Salud Publica Mex 2009, 51(Suppl 4):S562-S573.

22. Gómez LM, Hernández-Prado B, Morales C, Shamah-Levy T: Physical activity and overweight/obesity in adult Mexican population. The Mexican National Health and Nutrition Survey 2006. Salud Publica Mex 2009, 51(Suppl 4):s621-s629.

23. González-Castell D, González-Cossío T, Barquera S, Rivera JA: Contribution of processed foods to the energy, macronutrient and fiber intakes of Mexican children aged 1 to 4 years. Salud Plublica Mex 2007, 49(5):345-356.

24. Mensink RP, Zock PL, Kester ADM, Katan MB: Effects of dietary fatty acids and carbohydrates on the ratio of serum total to HDL cholesterol and 
on serum lipids and apolipoproteins: a meta-analysis of 60 controlled trials. Am J Clin Nutr 2003, 77(5):1146-1155.

25. Mozaffarian D, Willett WC: Trans fatty acids and cardiovascular risk: a unique cardiometabolic imprint? Curr Atheroscler Rep 2007, 9(6):486-493.

26. Ramírez-Silva I, Villalpando S, Moreno-Saracho JE, Bernal-Medina D: Fatty acids intake in the Mexican population. Results of the National Nutrition Survey 2006. Nutr Meatb (Lond) 2011, 8(1):33.

27. Bey L, Hamilton MT: Suppression of skeletal muscle lipoprotein lipase activity during physical inactivity: a molecular reason to maintain daily low-intensity activity. J Physiol 2003, 551(Pt2):673-682.

28. Haffner SM: Dyslipidemia management in adults with diabetes. Diabetes Care 2004, 27(Suppl 1):S68-S71.

29. National Cholesterol Education Program (NCEP) Expert Panel on Detection, Evaluation, and Treatment of High Blood Cholesterol in Adults (Adult Treatment Panel III): Third Report of the National Cholesterol Education Program (NCEP) Expert Panel on Detection, Evaluation, and Treatment of High Blood Cholesterol in Adults (Adult Treatment Panel III) final report. Circulation 2002, 106(25):3143-3421.

30. Davis CE, Williams DH, Oganov RG, Tao SC, Rywik SL, Stein Y, Little JA: Sex difference in high density lipoprotein cholesterol in six countries. Am J Epidemiol 1996, 143(11):1100-1106.

31. Kim HJ, Park HA, Cho YG, Kang JH, Kim KW, Kang JH, Kim NR, Chung WC, Kim $\mathrm{CH}$, Whang DH, Park JK: Gender difference in the level of HDL cholesterol in Korean adults. Korean J Fam Med 2011, 32:173-181.

32. Rojas-Martinez R, Aguilar-Salinas CA, Jiménez-Corona A: Optimal Cutoff points for the detection of undiagnosed type 2 diabetes, hypertension and metabolic syndrome in Mexican adults. Salud Publica Mex 2012, 54:13-19.

33. Wildman RP, Muntner P, Reynolds K, McGinn AP, Rajpathak S, Wylie-Rosett J, Sowers MR: The obese without cardiometabolic risk factor clustering and the normal weight with cardiometabolic risk factor clustering. Arch Intern Med 2008, 168(15):1617-1624.

34. Nasila Sungwacha J, Tyler J, Longo-Mbenza B, Lasi On'Kin JB, Gombet T, Erasmus RT: Assessing clustering of metabolic syndrome components available at primary care for Bantu Africans using factor analysis in the general population. BMC Res Notes 2013, 12(6):228.

doi:10.1186/1471-2458-14-1056

Cite this article as: Pedroza-Tobias et al: Classification of metabolic syndrome according to lipid alterations: analysis from the Mexican National Health and Nutrition Survey 2006. BMC Public Health

2014 14:1056.

\section{Submit your next manuscript to BioMed Central and take full advantage of:}

- Convenient online submission

- Thorough peer review

- No space constraints or color figure charges

- Immediate publication on acceptance

- Inclusion in PubMed, CAS, Scopus and Google Scholar

- Research which is freely available for redistribution 